Research Article

\title{
Computational and Simulation Analysis of Pull-Out Fiber Reinforced Concrete
}

\author{
Xia Zhao, ${ }^{1,2}$ Xiong-Jun He, ${ }^{1}$ Sheng Yan, ${ }^{1}$ and Nguyen Phan Anh ${ }^{1}$ \\ ${ }^{1}$ School of Transportation, Wuhan University of Technology, Wuhan 430070, China \\ ${ }^{2}$ Binzhou Polytechnic, Binzhou 256603, China \\ Correspondence should be addressed to Xia Zhao; yxzhaoxia@sina.com
}

Received 26 November 2013; Revised 15 January 2014; Accepted 16 January 2014 Published 3 April 2014

Academic Editor: Konstantinos I. Tserpes

Copyright (C) 2014 Xia Zhao et al. This is an open access article distributed under the Creative Commons Attribution License, which permits unrestricted use, distribution, and reproduction in any medium, provided the original work is properly cited.

The computational and simulation analysis of pull-out fiber reinforced concrete was investigated. The finite element analysis was used to make this modeling and analysis on this reinforced system and three parts (concrete matrix, the placed fiber reinforcement polymers (FRP), and resin layer) were studied. A constant load was directly applied on the free end of placed FRP and the deformation, von Mises stress, displacement, and strain of these three analyzed parts were obtained. Meanwhile, the specimen system of bonding strength and strain was calculated by the method of ABAQUS. The results showed that, with the constant load, the von Mises stress, deformation, and strain appeared in these three parts, and the maximum values in both FRP and resin layer were shown at the free end side, which provides an accurate description of the rupture mode.

\section{Introduction}

Concrete is the most widely used construction material in large quantities for its low cost and wide availability $[1,2]$. However, it suffers from low tensile strength and limited strain capacity, which gives rise to formation of microcracks in a loading state. Microcracks have an enormous influence on the durability and the formed cracks accelerate the deterioration by increasing the permeability of the matrix through freezing-and-thawing damage, alkali silica reaction, chloride penetration, and other mechanisms [3, 4]. Nowadays, the researchers find that the fiber reinforcement polymers (FRP) have created an extensive field to control the matrix cracks. The structures achieve a good strengthening effect with FRP in mechanical and durability properties. Their high stiffness, chemical resistance, tensile strength, and fire resistance make them attractive for the next generation high performance reinforced composites materials of the 21st century [5-10].

Prior works on FRP reinforced concrete have focused on the finite element analysis modeling and simulation in the literature [11-30]. Wu et al. [31] studied the cracking behavior and interfacial debonding fracture in FRP-strengthened concrete beams and a finite element analysis was performed to obtain the different types of debonding propagation along FRP-concrete interface and crack distribution in matrix. Benzarti et al. [32] presented a coupled damage model to predict the durability of concrete elements strengthened by external bonding of FRP plates and their numerical results and experimental tests showed that the model captures well the debonding fracture initiation. An experimental investigation of the fatigue behavior of FRP-concrete was investigated by Carloni et al. [33] and they found that the length of stress transfer zone during fatigue loading was smaller than the stress transfer zone associated with the cohesive crack under quasistatic loading; also the postfatigue results suggested the possibility of a different debonding mechanism during fatigue loading.

In this paper, the finite element analysis [34, 35] was used to make this modeling and analysis on this pull-out $\mathrm{FRP} /$ concrete system. Each specimen of bonding strength and strain was calculated by ABAQUS method. The concrete matrix, the strengthening FRP, and resin layer were modeled individually as damageable materials with a constant loading. The von Mises stress, strain, deformation, and displacement were all given to analyze this rupture mode of selected composites. 
TABLE 1: Young's modulus and Poisson's ratio of three analyzed parts.

\begin{tabular}{lcc}
\hline Materials & Young's modulus/GPa & Poisson's ratio \\
\hline Concrete matrix & $3.152 \times 10^{4}$ & 0.3 \\
FRP & $1.618 \times 10^{5}$ & 0.2 \\
Resin layer & $5.21 \times 10^{3}$ & 0.39 \\
\hline
\end{tabular}

TABLE 2: Summary of testing results.

\begin{tabular}{lccccccc}
\hline Specimen & $L(\mathrm{~mm})$ & $b_{b}(\mathrm{~mm})$ & $t_{p}(\mathrm{~mm})$ & $f_{c}(\mathrm{MPa})$ & $E_{c}(\mathrm{MPa})$ & $P_{\text {exp }}(\mathrm{kN})$ & Failure \\
\hline $30 \mathrm{MPa}-250-10$ & 250 & 10.29 & 1.22 & 30 & 31,520 & 26.6 & $\mathrm{D}$ \\
\hline
\end{tabular}

TABLE 3: The detailed dimensions of each three parts.

\begin{tabular}{lcccccccccc}
\hline Sample & $L_{c}(\mathrm{~mm})$ & $b_{c}(\mathrm{~mm})$ & $t_{c}(\mathrm{~mm})$ & $L_{f}(\mathrm{~mm})$ & $b_{f}(\mathrm{~mm})$ & $t_{f}(\mathrm{~mm})$ & $L_{r}(\mathrm{~mm})$ & $b_{r}(\mathrm{~mm})$ & $t_{r}(\mathrm{~mm})$ & $P(\mathrm{~N})$ \\
\hline $30 \mathrm{MPa}-250-10$ & 350 & 300 & 180 & 350 & 1.22 & 10.29 & 250 & 1 & 10.29 & 26600 \\
\hline
\end{tabular}

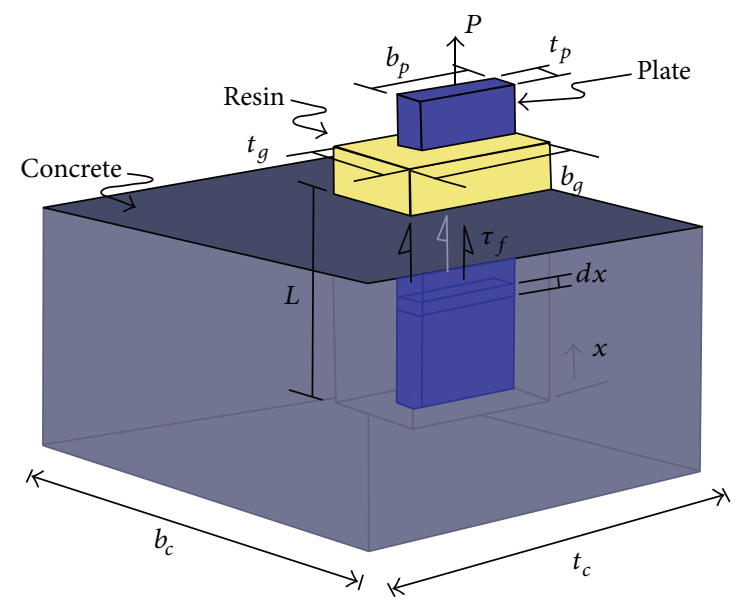

Figure 1: Simplified model of FRP-concrete.

\section{Computational and Simulation Modes}

2.1. Model Design. In order to confirm the analysis of the simulation program and the further studying about the relationship between bonding and slip, a finite element analysis was performed by using ABAQUS 6.8-1 to calculate and simulate the pull-out FRP/concrete system. In the pullout FRP/concrete model, the main component includes four parts: concrete, FRP, resin, and the bond interface between concrete and FRP. All components were modeled by using 8 node linear brick, which reduced integration and hourglass control (C3D8R).

As a simplified model of pull-out FRP/concrete system, which was shown in Figure 1, it included the concrete matrix, FRP, and the resin. Young's modulus and the Poisson's ratio of these three parts were shown in Table 1.

2.2. Modeling Procedure. Before the model procedures, we assume that the bending effect of FRP is ignored. Meanwhile, only the shear force appears in adhesive layer and the size of each part still stays in a constant value and no deformation occurred.
For each component of this modeled system, the stressstrain curve of concrete follows the mathematical model investigated by Todeschini et al. [36]. The size of the concrete block was $350 \times 300 \times 180 \mathrm{~mm}$, which was shown in Figure 2 . Concrete cylinders were used to define material properties including the compress strength and Young's modulus in Table 2. FRP is assumed as behaving a linear-elastically condition which showed the failure stress and strain in longitudinal tension. At the failure point, FRP loses its tensile strength. The type of constitutive behavior of resin is simulated by an elastic-plastic model with strain hardening for quasistatic response during pull-out testing. In order to define this behavior, the properties of resin were given below, such as Young's modulus of $5210 \mathrm{MPa}$, the tensile strength of $16 \mathrm{MPa}$, and Poisson's ratio of 0.39. All components were followed the American Standard ASTM D638. A finite element analysis is used to make this modeling and analysis on this reinforced system. The details of this modeling procedure are as follows.

(1) Define a 3D concrete block with a sized groove placed in the middle of the matrix. The size of groove is $(1+$ $1.22+1) \times 10.29 \mathrm{~mm}$.

(2) Define a 3D deformable FRP plate $(1.22 \times 10.29 \times$ $L_{\text {FRP }} \mathrm{mm}$ ) which lays in the groove. A constant load is applied at the free size of FRP: $L_{\mathrm{FRP}}>L=250$, where $L_{\mathrm{FRP}}$ is length of FRP strip and $L$ stands for bond length of FRP as experimental test.

(3) Define two layers of the deformable coated resin $(1 \times$ $10.29 \times 250 \mathrm{~mm})$. Resin layer is coated between the matrix and FRP. The detailed dimensions of concrete matrix, FRP plate and resin layer are shown in Table 3, where $b_{c}, t_{c}, b_{g}, t_{g}, b_{p}$, and $t_{p}$ are the width and length of concrete matrix, the placed grooves, and FRP, respectively. $\tau_{f}$ represents the maximum value of interfacial shear stress and $L$ shows the placed length of FRP in matrix. A constant load $(26600 \mathrm{~N})$ was applied on the free end of placed FRP.

(4) Define interfacial bond between FRP plate and concrete and FRP plate and resin layer by tying constraint 


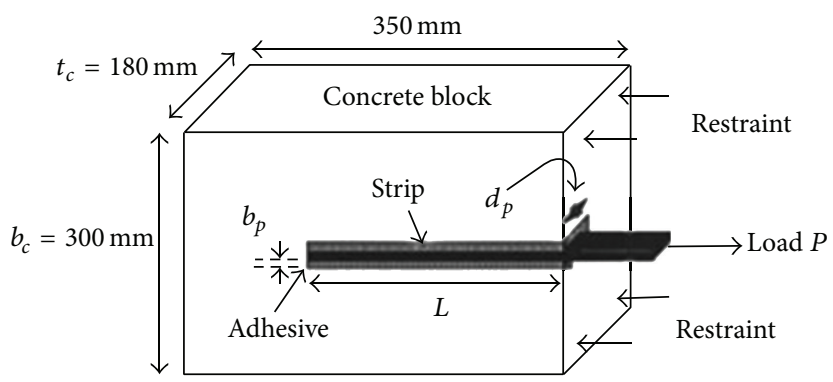

(a)
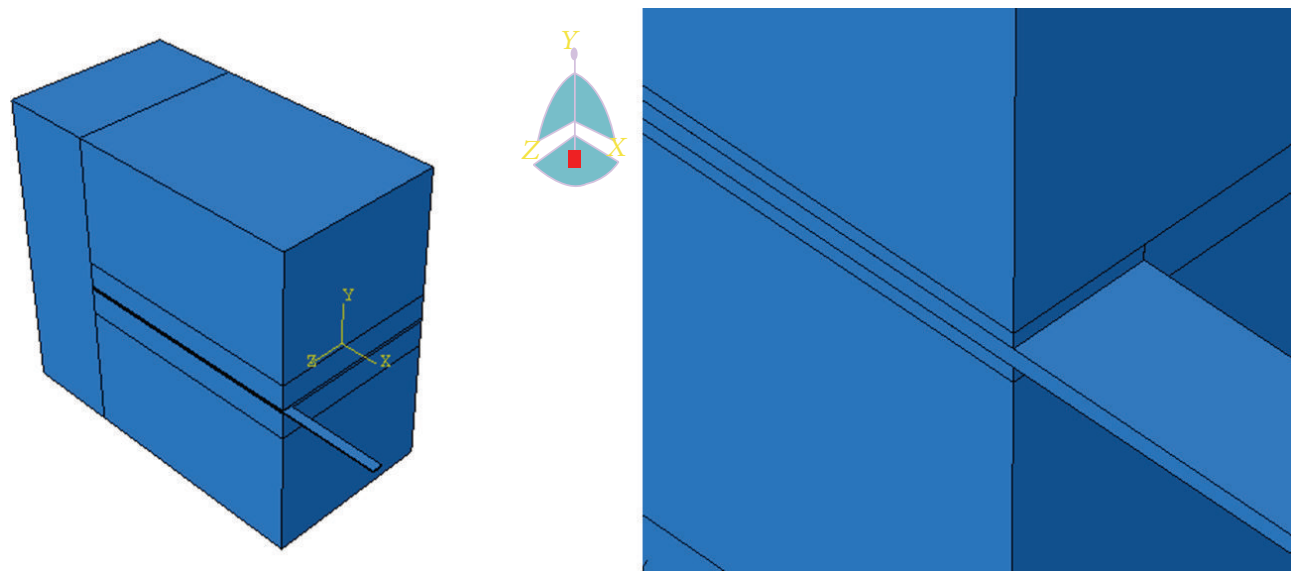

(b)

FIGURE 2: The detailed reinforced system model.

of two adjacent surfaces. In this modeling, the tie constraint surfaces include concrete-first resin layer, first resin layer-FRP, FRP-second resin layer, and second resin layer-concrete. The defined model is shown in Figure 2.

2.3. Mesh, Loading, and Boundary Condition. As one important step in this modeling, a detailed meshing [37] can ensure a relatively accurate modeling result. Structural mesh generation technique was applied in this modeling. Mesh of concrete matrix, FRP plate, and resin layer are all shown in Figure 3. A constant load $(26600 \mathrm{~N})$ is applied at the free end of FRP plate and the corresponding boundary condition was followed as the experimental test, which was done by Seracino et al. [38]. The loading and boundary condition were shown in Figure 4.

2.4. Analysis Algorithm and Control Solutions. In this simulation, a directly nonlinear analysis technique was employed and this technique followed the method of Newton-Rapson. In the modeling procedures, the system stayed in a static loading condition. Automatic time step was applied with set 1. The maximum number was 100 and the increment size included the initial value 1 , the minimum value $1 \mathrm{E}-05$, and the maximum value 1 .

\section{Analysis}

3.1. Calculation. In order to satisfy the accuracy of the model, the bond interface characteristics of the analytical model were calculated by using the method of finite element analysis. In the Seracino et al. [39] model, the predicted IC debonding failures of FPR strengthening system with a constant loading can be calculated by

$$
P_{\mathrm{IC}}=\alpha_{p} 0.85 \varphi_{f}^{0.25} f_{c}^{0.3} \sqrt{L_{\mathrm{per}} E_{p} A_{p}}<f_{\text {rupt }} A_{p} .
$$

As calculated in (1) and previous design, results of each specimen are shown in Table 4. This thesis uses ABAQUS software to simulate finite element analysis method. All specimen systems were broken down finally.

3.2. Deformation. With the constant loading, a deformation was obtained in FRP plate. No deformation appeared in the area of $X Y$ plane and $Y Z$ plane; but a remarkable deformation occurred in $X Z$ plane and it was bended inwards. According to the symmetric principle, the deformation was cancelled in $X Y$ plane and $Y Z$ plane. However, a bending moment was obtained for the constant load in $X Z$ plane. The deformation of this modeling was shown in Figure 5 and an evident deformation occurred at the edge between matrix and FRP plate. 

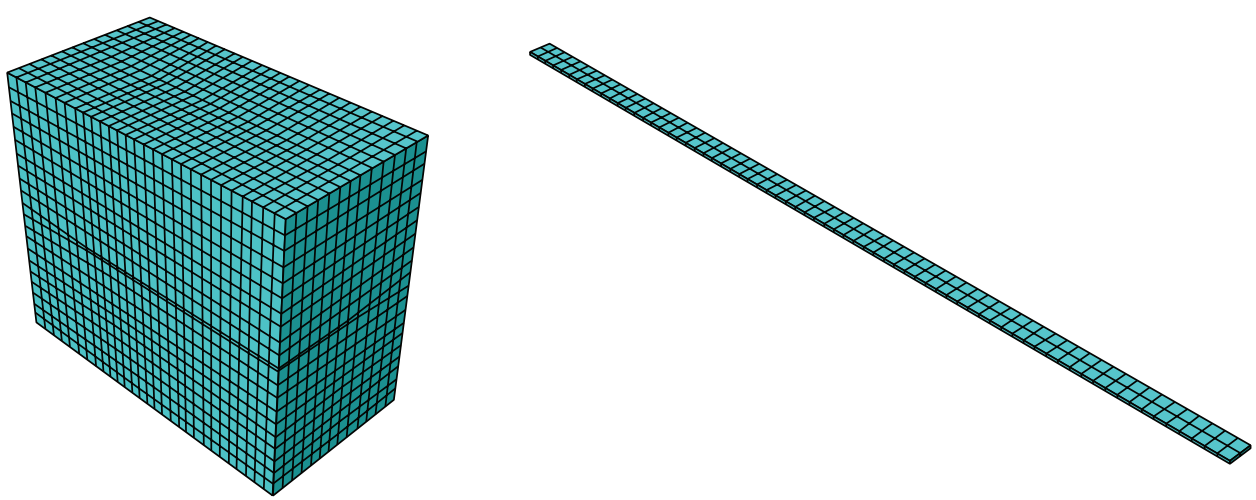

(a)
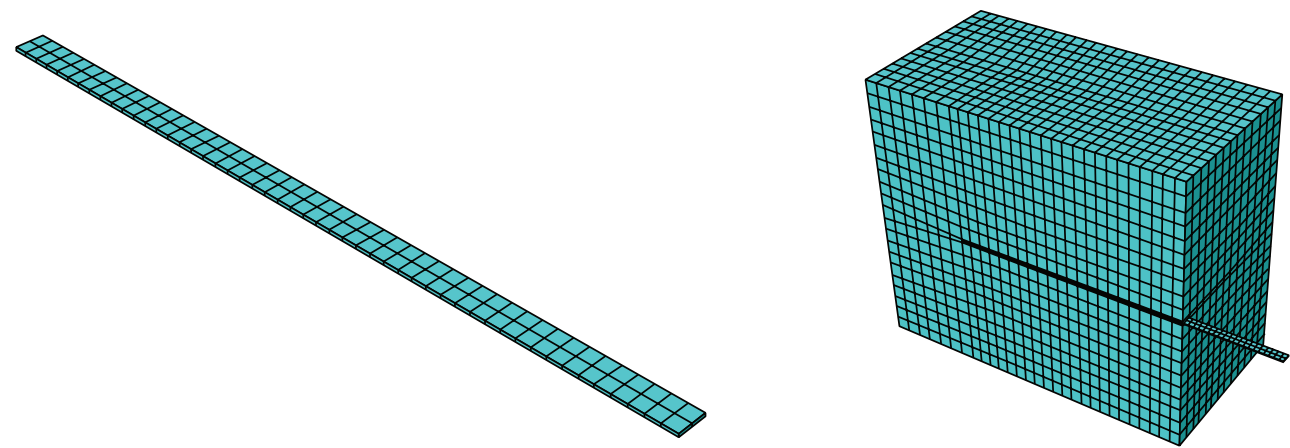

(b)

FIGURE 3: Mesh of concrete matrix, FRP plate, resin layer, and the reinforced concrete system.
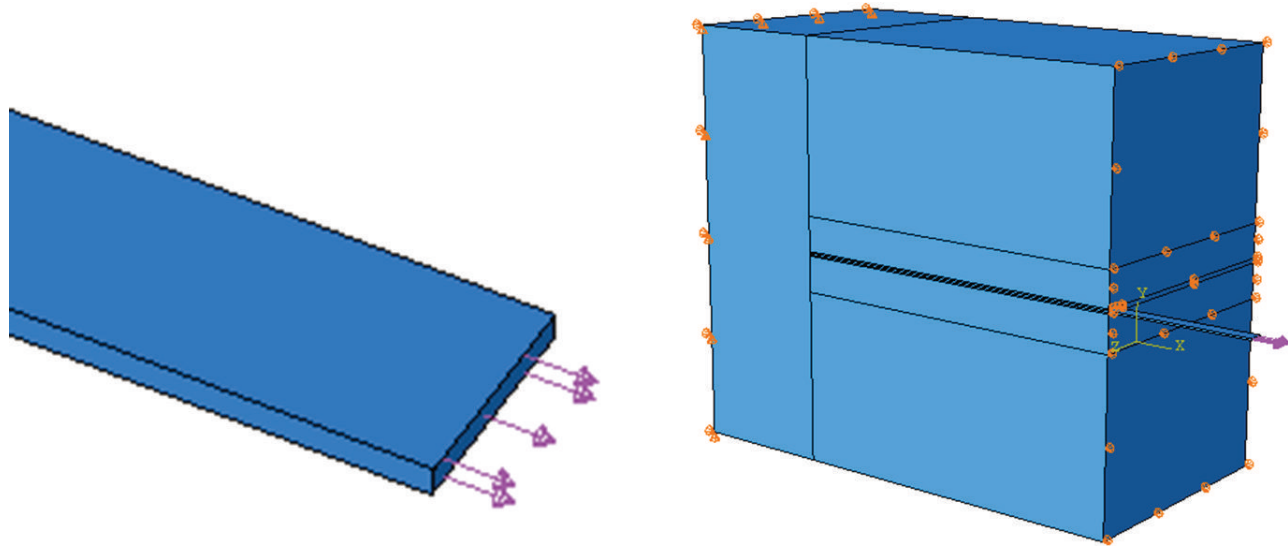

FIGURE 4: The loading and boundary condition of reinforced concrete system.

TABLE 4: Calculation for each specimen test by Abaqus software.

\begin{tabular}{lcc}
\hline Specimen & Bond strength $(\mathrm{kN})$ & $\varepsilon_{\max }(\mathrm{mm})$ \\
\hline $30 \mathrm{MPa}-100-10$ & 20.4 & 0.009133 \\
$30 \mathrm{MPa}-150-10$ & 23.2 & 0.010213 \\
$30 \mathrm{MPa}-200-10$ & 27.9 & 0.012238 \\
$30 \mathrm{MPa}-250-10$ & 26.6 & 0.0118 \\
$30 \mathrm{MPa}-300-10$ & 26.0 & 0.011452 \\
$30 \mathrm{MPa}-350-10$ & 23.0 & 0.010106 \\
\hline
\end{tabular}



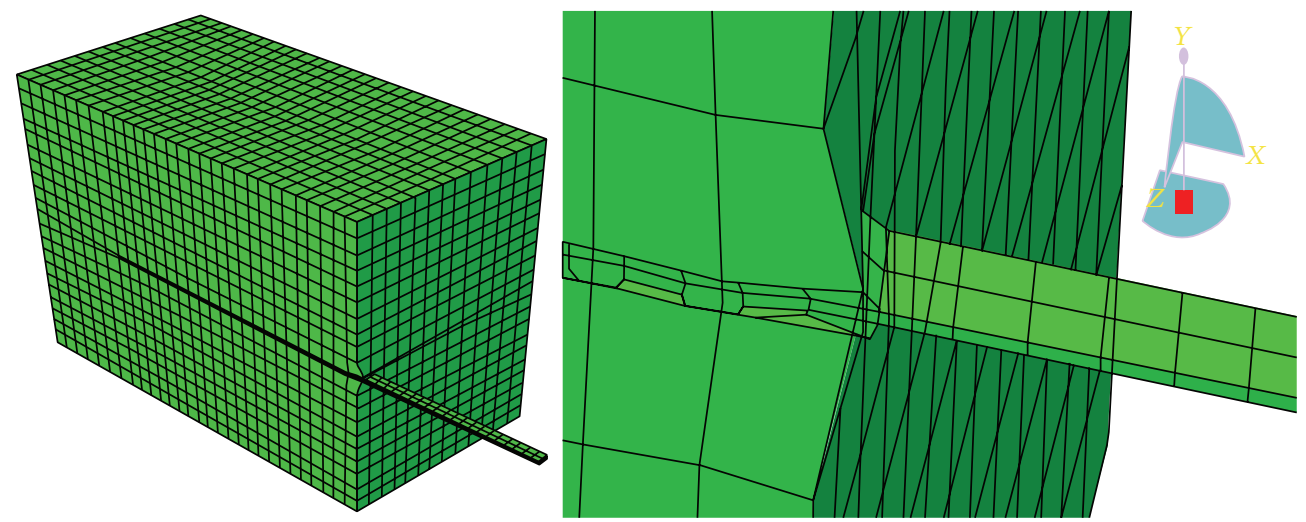

FIGURE 5: Deformation of FRP in this modeling.
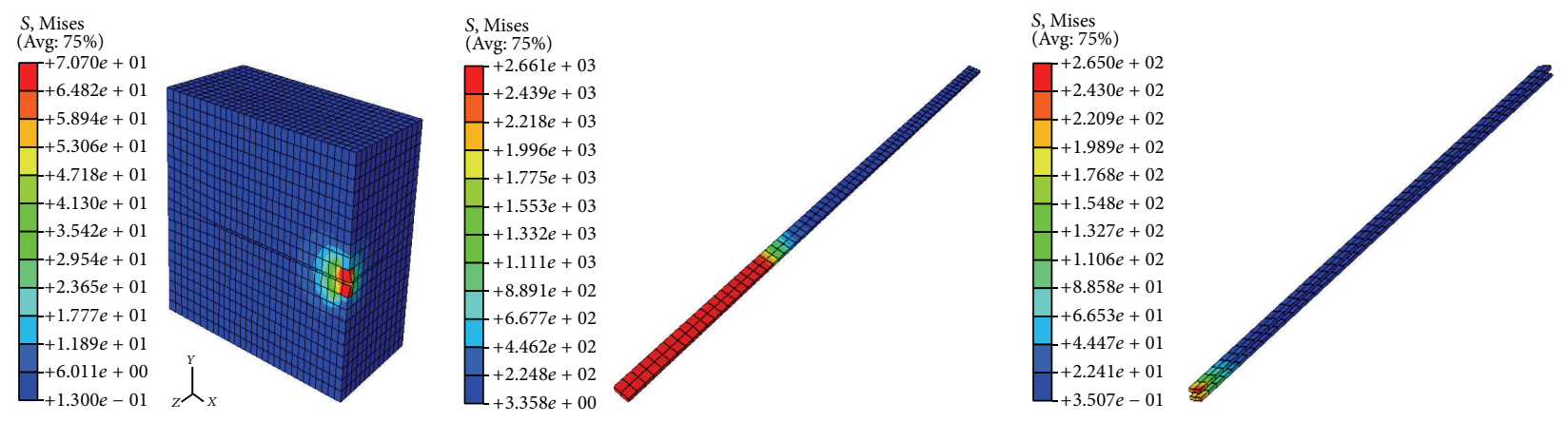

FIgURE 6: von Mises stress of concrete, FRP plate, and resin layer.
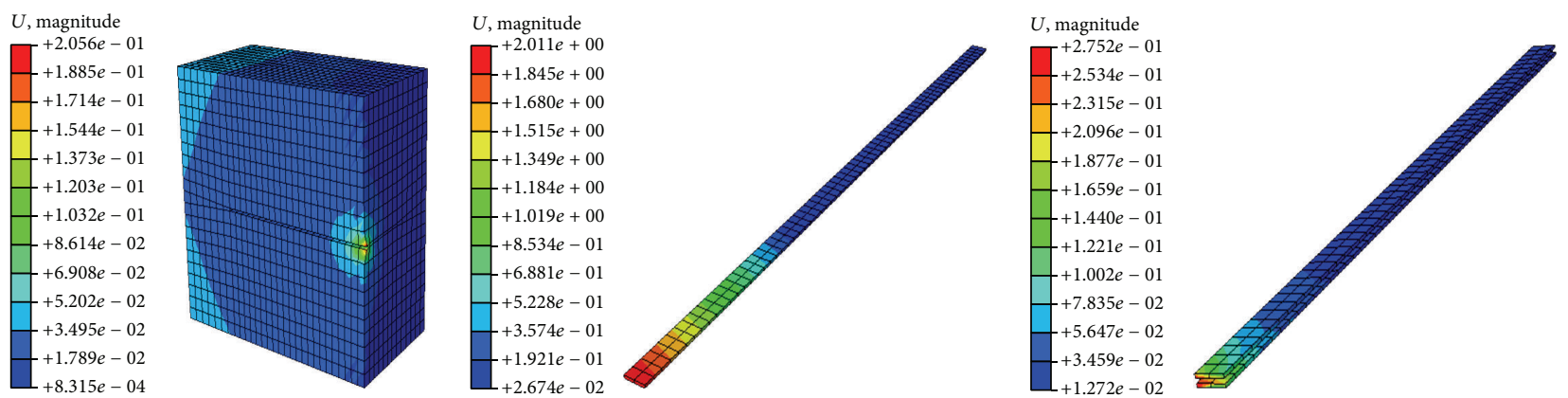

FIGURE 7: Displacement of concrete, FRP plate, and resin layer.

3.3. von Mises Stress. von Mises stress [40, 41] was always used to describe the distribution of stress, and the color in each mesh showed the stress value. The stress means to be increased when the color turns from blue to red, and the von Mises stress values can be obtained. The von Mises stress of concrete matrix, FRP plate, and resin layer were all shown in Figure 6. The maximum von Mises stress $\left(2.661 \times 10^{3} \mathrm{MPa}\right)$ value was obtained at the edge between matrix and FRP plate. Meanwhile, the maximum von Mises stress of FRP plate $2.661 \times 10^{3} \mathrm{MPa}$ and resin layer $2.661 \times 10^{2} \mathrm{MPa}$ appeared at the board edge of FRP plate.

3.4. Displacement. The displacement showed the degree of deformation of concrete matrix, FRP plate, and resin layer, which indirectly reflected the bonding strength. The maximum displacement of tested three parts (Figure 7) appeared at the edge of contact point, and the maximum values were $0.2056 \mathrm{~mm}, 2.011 \mathrm{~mm}$, and $0.2752 \mathrm{~mm}$, respectively. The displacement decreased with the deeper groove of concrete, which showed that the bonding strength was much higher and a greater durability property was obtained.

3.5. Strain. The simulated strain showed the deformation resistance ability, which indirectly reflected the displacement and bonding strength. The same distribution trends were obtained in Figure 8, and the maximum value all occurred at the contact place. All the maximum strain was $2.188 \times 10^{-3}$, $1.644 \times 10^{-2}$, and $4.637 \times 10^{-2}$, respectively. 


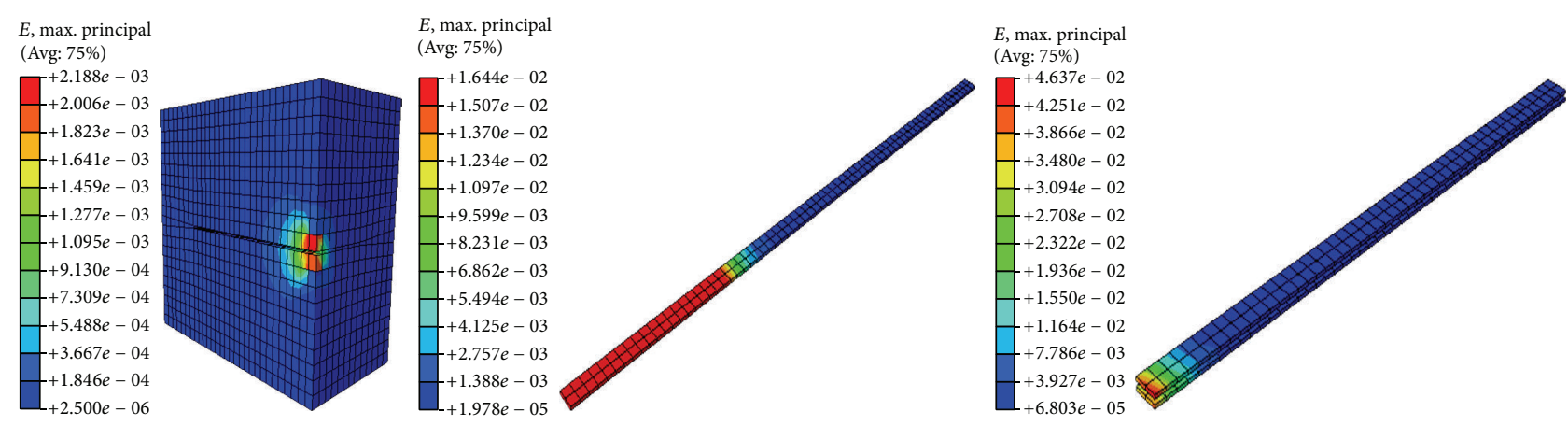

FIGURE 8: Strain of concrete, FRP plate, and resin layer.

\section{Conclusions}

In this paper, the computational and modeling analysis of the pull-out FRP/concrete system was studied systematically. A finite element analysis was used in this modeling procedure. Each specimen system of bonding strength and strain was calculated by the method of ABAQUS. All the three parts, concrete matrix, FRP, and resin layer, were studied in this analysis individually. A constant load $(26600 \mathrm{~N})$ was applied on the free side of the placed FRP. Deformation, von Mises stress, displacement, and strain of each individual part were obtained and the maximum values all occurred at the edge of the contact point. Meanwhile, the values decreased with the deeper groove of concrete, which showed that the higher bonding strength was gained in the deeper groove, and the contact point was the weakest zone in this pull-out FRP/concrete system.

Further researches are needed to obtain a deeper analysis of pull-out FRP reinforced concrete. Also, the detailed pulling-out process (elastic stage, elastic softening stage, debonding stage, and softening-debonding stage) and slip and shear stress at the interfacial bond shall be explored. We believe that our results at least in the trend are helpful for the research of FRP reinforced concrete system.

\section{Conflict of Interests}

The authors declare that there is no conflict of interests regarding the publication of this paper.

\section{Acknowledgment}

The authors would like to express appreciation for the financial support by the Natural Science Foundation of China (51178361).

\section{References}

[1] F. M. Lea, The Chemistry of Cement and Concrete, Edward Arnold, London, UK, 3rd edition, 1976.

[2] H. F. W. Taylor, Cement Chemistry, Thomas Telford, London, UK, 2nd edition, 1998.

[3] B. M. Wang, Y. Zhang, and S. Liu, "Influence of carbon nanofibers on the mechanical performance and microstructure of cement-based materials," Nanoscience and Nanotechnology Letters, vol. 5, no. 10, pp. 1112-1118, 2013.

[4] Z. S. Metaxa, M. S. Konsta-Gdoutos, and S. P. Shah, "Carbon nanofiber cementitious composites: effect of debulking procedure ondispersion and reinforcing efficiency," Cement and Concrete Composites, vol. 36, pp. 25-32, 2013.

[5] T. C. Triantafillou, "Shear strengthening of reinforced concrete beams using epoxy-bonded FRP composites," ACI Structural Journal, vol. 95, no. 2, pp. 107-115, 1998.

[6] R. El-Hacha and S. H. Rizkalla, "Near-surface-mounted fiberreinforced polymer reinforcements for flexural strengthening of concrete structures," ACI Structural Journal, vol. 101, no. 5, pp. 717-726, 2004.

[7] L. Lam and J. G. Teng, "Strength models for fiber-reinforced plastic-confined concrete," Journal of Structural Engineering, vol. 128, no. 5, pp. 612-623, 2002.

[8] L. Koutas and T. C. Triantafillou, "Use of anchors in shear strengthening of reinforced concrete T-beams with FRP," Journal of Composites for Construction, vol. 17, no. 1, pp. 101-107, 2013.

[9] H. Wang and A. Belarbi, "Ductility characteristics of fiberreinforced-concrete beams reinforced with FRP rebars," Construction and Building Materials, vol. 25, no. 5, pp. 2391-2401, 2011.

[10] G. Ma, H. Li, and Z. Duan, "Repair effects and acoustic emission technique-based fracture evaluation for predamaged concrete columns confined with fiber-reinforced polymers," Journal of Composites for Construction, vol. 16, no. 6, pp. 626-639, 2012.

[11] H.-T. Hu, F.-M. Lin, and Y.-Y. Jan, "Nonlinear finite element analysis of reinforced concrete beams strengthened by fiberreinforced plastics," Composite Structures, vol. 63, no. 3-4, pp. 271-281, 2004.

[12] A. M. Malek and H. Saadatmanesh, "Analytical study of reinforced concrete beams strengthened with web-bonded fiber reinforced plastic plates or fabrics," ACI Structural Journal, vol. 95, no. 3, pp. 343-352, 1998.

[13] J. W. Tedesco, J. M. Stallings, and M. El-Mihilmy, "Finite element method analysis of a concrete bridge repaired with fiber reinforced plastic laminates," Computers and Structures, vol. 72, no. 1, pp. 379-407, 1999.

[14] E. Cosenza, G. Manfredi, and R. Realfonzo, "Behavior and modeling of bond of FRP rebars to concrete," Journal of Composites for Construction, vol. 1, no. 2, pp. 40-51, 1997.

[15] C. Na and H.-G. Kwak, "A numerical tension-stiffening model for ultra high strength fiber-reinforced concrete beams," Computers and Concrete, vol. 8, no. 1, pp. 1-22, 2011. 
[16] H. Hu and W. C. Schnobrich, "Constitutive modeling of concrete by using nonassociated plasticity," Journal of Materials in Civil Engineering, vol. 1, no. 4, pp. 199-216, 1989.

[17] B. Ferracuti, M. Savoia, and C. Mazzotti, "A numerical model for FRP-concrete delamination," Composites B: Engineering, vol. 37, no. 4-5, pp. 356-364, 2006.

[18] S. K. Padmarajaiah and A. Ramaswamy, "A finite element assessment of flexural strength of prestressed concrete beams with fiber reinforcement," Cement and Concrete Composites, vol. 24, no. 2, pp. 229-241, 2002.

[19] M. Samaan, A. Mirmiran, and M. Shahawy, "Model of concrete confined by fiber composites," Journal of Structural Engineering, vol. 124, no. 9, pp. 1025-1031, 1998.

[20] X. Z. Lu, L. P. Ye, J. G. Teng, and J. J. Jiang, "Meso-scale finite element model for FRP sheets/plates bonded to concrete," Engineering Structures, vol. 27, no. 4, pp. 564-575, 2005.

[21] J. F. Chen and J. G. Teng, "Anchorage strength models for FRP and steel plates bonded to concrete," Journal of Structural Engineering, vol. 127, no. 7, pp. 784-791, 2001.

[22] J. G. Teng, J. W. Zhang, and S. T. Smith, "Interfacial stresses in reinforced concrete beams bonded with a soffit plate: a finite element study," Construction and Building Materials, vol. 16, no. 1, pp. 1-14, 2002.

[23] R. S. Y. Wong and F. J. Vecchio, “Towards modeling of reinforced concrete members with externally bonded fiber-reinforced polymer composites," ACI Structural Journal, vol. 100, no. 1, pp. 47-55, 2003.

[24] X. Z. Lu and J. J. Jiang, "A concrete constitutive relationship with various damage models," China Civil Engineering Journal, vol. 36, no. 11, pp. 70-74, 2003.

[25] L. Skarzynśki and J. Tejchman, "Determination of representative volume element in concrete under tensile deformation," Computers and Concrete, vol. 9, no. 1, pp. 35-50, 2012.

[26] X. Z. Lu, J. G. Teng, L. P. Ye, and J. J. Jiang, "Bond-slip models for FRP sheets/plates bonded to concrete," Engineering Structures, vol. 27, no. 6, pp. 920-937, 2005.

[27] L. Lam and J. G. Teng, "Strength models for fiber-reinforced plastic-confined concrete," Journal of Structural Engineering, vol. 128, no. 5, pp. 612-623, 2002.

[28] M. N. Youssef, M. Q. Feng, and A. S. Mosallam, "Stress-strain model for concrete confined by FRP composites," Composites B: Engineering, vol. 38, no. 5-6, pp. 614-628, 2007.

[29] T. Jiang and J. G. Teng, "Analysis-oriented stress-strain models for FRP-confined concrete," Engineering Structures, vol. 29, no. 11, pp. 2968-2986, 2007.

[30] M. R. Spoelstra and G. Monti, "FRP-confined concrete model," Journal of Composites for Construction, vol. 3, no. 3, pp. 143-150, 1999.

[31] Z. M. Wu, J. J. Zheng, and X. Wu, "Modeling of debonding and fracture process of FRP-strengthened concrete beams via fracture mechanics approach," Journal of Reinforced Plastics and Composites, vol. 32, no. 28, pp. 1-13., 2013.

[32] K. Benzarti, F. Freddi, and M. Frémond, "A damage model to predict the durability of bonded assemblies. Part I: debonding behavior of FRP strengthened concrete structures," Construction and Building Materials, vol. 25, no. 2, pp. 547-555, 2011.

[33] C. Carloni, K. V. Subramaniam, M. Savoia, and C. Mazzotti, "Experimental determination of FRP-concrete cohesive interface properties under fatigue loading," Composite Structures, vol. 94, no. 4, pp. 1288-1296, 2012.
[34] X. Zhang, H. Li, X. Feng et al., "Mechanical behavior of steel-encased concrete filled prefabricated FRP tubes short column under axial compression based on ABAQUS," Applied Mechanics and Materials, vol. 256-259, no. 12, pp. 749-753, 2012.

[35] J. Song, H. Yan, Z. Guo et al., "Nonlinear finite element analysis and simulation of nacelle-cover of MW-class wind turbine based on ABAQUS," Machine Building \& Automation, vol. 39, no. 6, pp. 122-125, 2010.

[36] C. E. Todeschini, A. C. Bianchini, and C. E. Kesler, "Behavior of concrete columns reinforced with high strength steels," Aci Materials Journal, vol. 61, pp. 701-716, 1964.

[37] J. F. Chen and Y. Tao, Finite Element Modeling of FRP-toConcrete Bond Behavior Using the Concrete Damage Plasticity Theory Combined with a plastic degradation Model, Springer, Beijing, China, 5th edition, 2010.

[38] R. Seracino, N. M. Jones, M. S. M. Ali, M. W. Page, and D. J. Oehlers, "Bond strength of near-surface mounted FRP strip-toconcrete joints," Journal of Composites for Construction, vol. 11, no. 4, pp. 401-409, 2007.

[39] R. Seracino, D. J. Oehlers, and S. Raizal, “Towards a generic model of the intermediate crack debonding resistance of plates adhesively bonded to concrete," in Proceedings of the International Symposium on bond behavior of FRP in Structures, International Institute of FRP in Construction, 2005.

[40] G. V. G. Rao, P. Mahajan, and N. Bhatnagar, "Micro-mechanical modeling of machining of FRP composites-cutting force analysis," Composites Science and Technology, vol. 67, no. 3-4, pp. 579593, 2007.

[41] M. Lesani, M. R. Bahaari, and M. M. Shokrieh, "Numerical investigation of FRP-strengthened tubular T-joints under axial compressive loads," Composite Structures, vol. 100, pp. 71-78, 2013. 

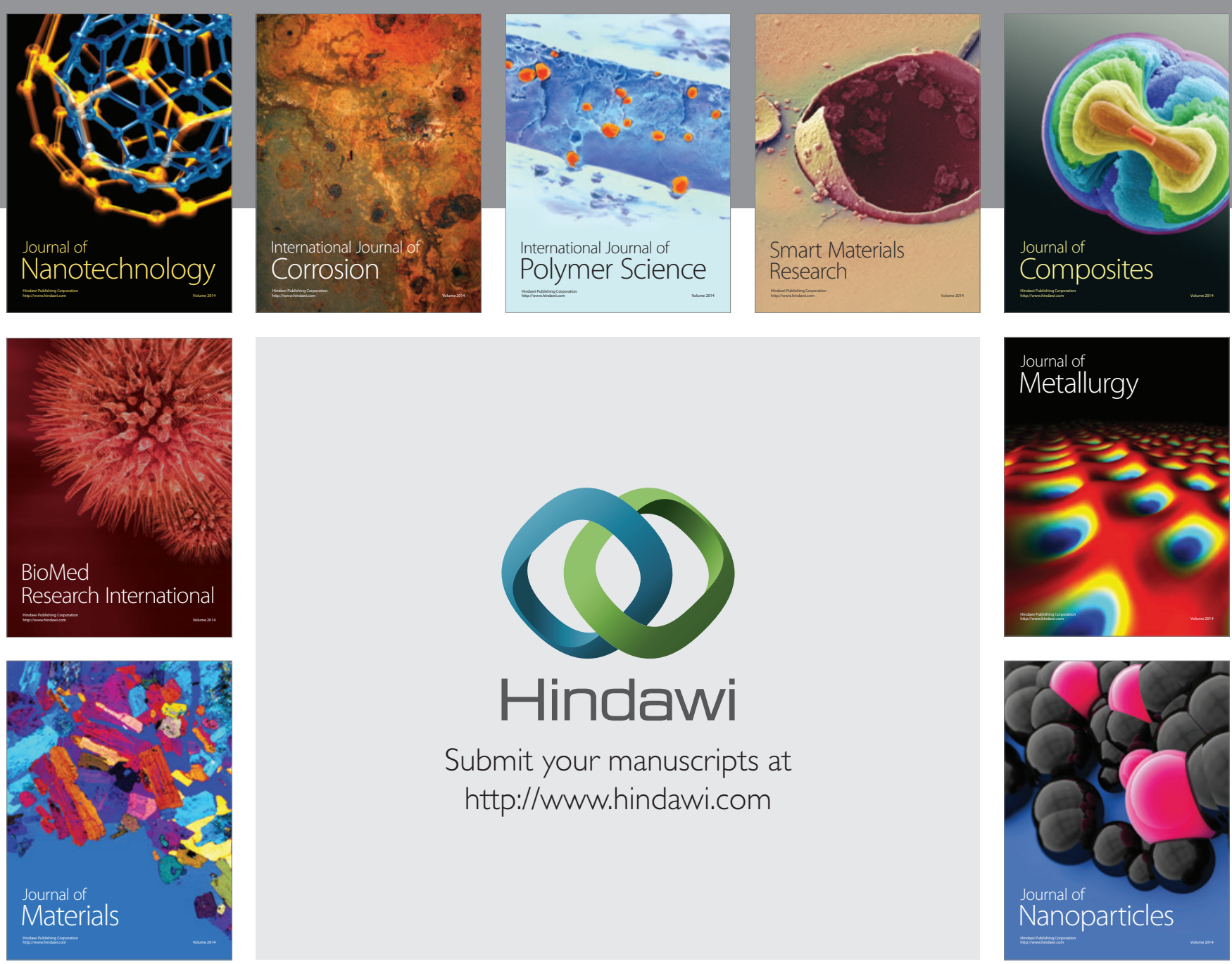

Submit your manuscripts at http://www.hindawi.com
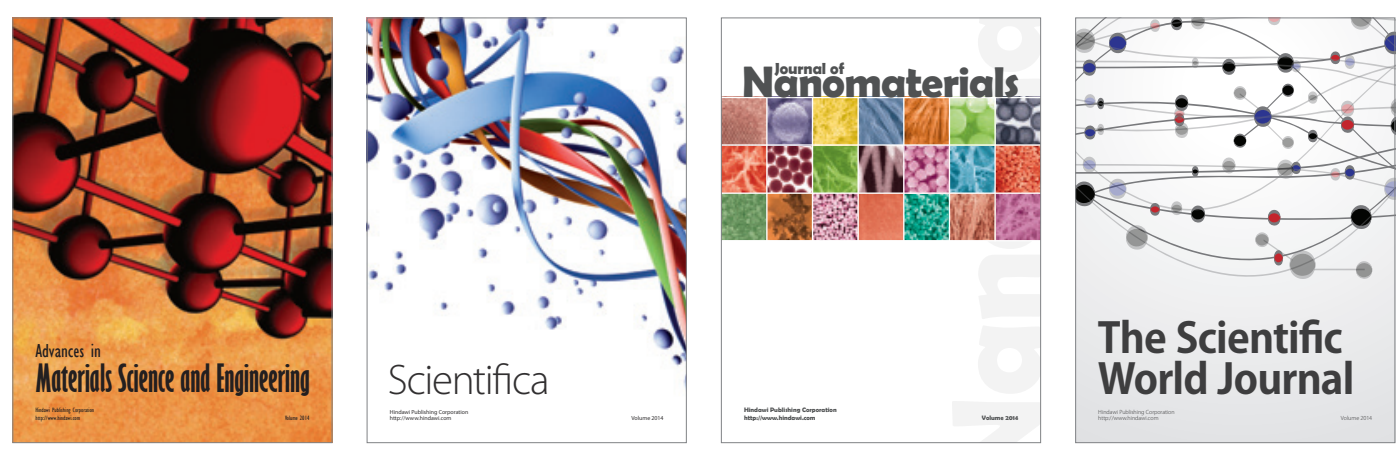

\section{The Scientific World Journal}
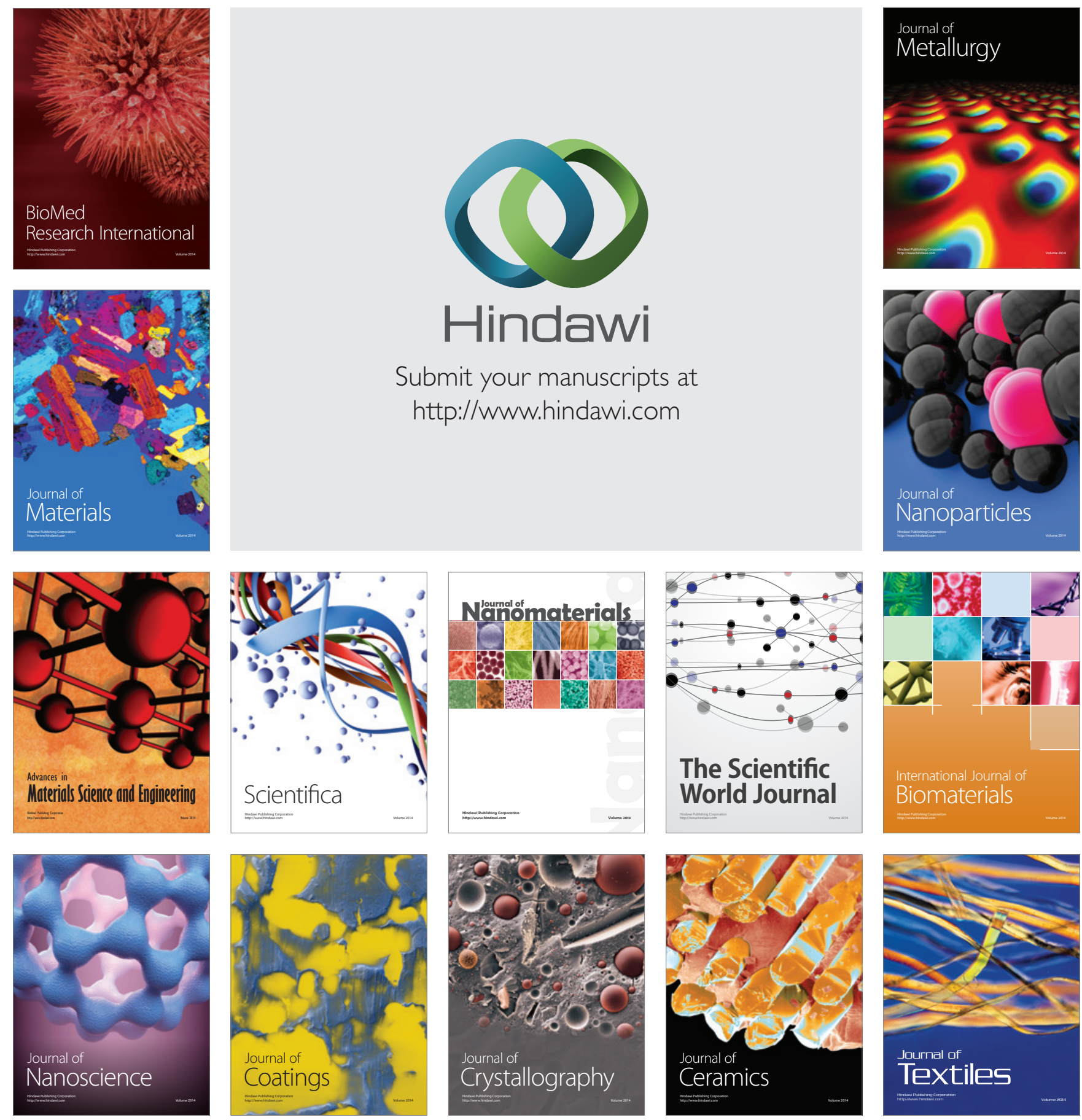